\title{
Early parental death and psychosocial risk factors for dementia: A case- control study in Europe
}

Running title: Early parental death in dementia

Authors: Josep L. Conde Sala ${ }^{\mathrm{a}, \mathrm{b}}$, Josep Garre-Olmo ${ }^{\mathrm{b}, \mathrm{c}}$

\section{Institutional affiliations}

${ }^{a}$ Institute of Neurosciences, University of Barcelona, Catalonia, Spain

${ }^{b}$ Aging, Disability and Health Research Group. Girona Biomedical Research Institute (IdIBGi),

Catalonia, Spain

c Department of Medical Sciences, University of Girona, Spain

\section{ORCID}

Josep L. Conde Sala https://orcid.org/0000-0003-4139-0458

Josep Garre-Olmo ～ㄴtps://orcid.org/0000-0002-7817-0814

Words in abstract: 218; Text: 3491; Tables: 5, Figures: 1, Supplementary tables: 2

\section{Corresponding author:}

Josep L. Conde-Sala

Faculty of Psychology. University of Barcelona

Passeig Vall d'Hebron, 171. 08035 Barcelona. Spain

Tel. (+34) 93 3125814; Fax: (+34) 93 4021368; E-mail: jllconde@ub.edu 


\begin{abstract}
Objectives: To assess the association between early parental death and the risk of dementia in adult life, and to examine the risk factors associated with early parental death in people with and without dementia.
\end{abstract}

Methods / Design: A population-based case-control study of a sample of 65,997 participants from the Survey of Health, Ageing and Retirement in Europe study. Early parental death was operationalized as parental death at the age of $\leq 16$ years. Main analyses were conducted using bivariate and multivariate logistic regression analyses.

Results: The odds ratio (OR) for dementia in individuals who experienced early parental death (father or mother) at the age of $\leq 16$ years was $1.83(95 \% \mathrm{Cl} 1.61-2.09)$ and 1.54 $(95 \% \mathrm{Cl} 1.35-1.76)$ adjusted for age, gender, and education. In the multivariate logistic regression analysis carried out with the whole sample, early parental death increased the risk of dementia $(\mathrm{OR}=1.50,95 \% \mathrm{Cl} 1.31-1.72)$, along with older age $(\mathrm{OR}=5.92,95 \% \mathrm{Cl} 4.86$ 7.17), neuroticism $(\mathrm{OR}=2.94,95 \% \mathrm{Cl} 2.61-3.31)$, low education level $(\mathrm{OR}=1.84,95 \% \mathrm{Cl} 1.64-$ 2.05) and low income $(\mathrm{OR}=1.49,95 \% \mathrm{Cl} 1.34-1.67)$.

Discussion: Early parental death ( $\leq 16$ years) was associated with an increased risk of dementia. We discuss the neurobiological markers associated with adverse childhood experiences (ACEs) and dementia as well as interventions to counteract the negative health effects on adults.

Key words: Dementia, Adverse childhood experiences, Early parental death, Biomarkers.

\title{
Key points
}


- Adverse childhood experiences (ACEs) have negative effects on adults' health.

- Early parental death ( $\leq 16$ years) is an ACE with a relevant risk for dementia.

- Cortisol, telomeres, c-reactive protein (CRP), and interleukin-6 (IL-6) are biomarkers of ACEs.

- Interventions are needed to counter the negative effects of ACEs on health. 


\section{INTRODUCTION}

It has been consistently documented ${ }^{1-5}$ that adverse experiences in childhood and adolescence have negative repercussions on adult life and health and may affect between 23.5\% and $35.0 \%$ of the population in Europe and the United States. ${ }^{1}$

The early death of parents has been one of the most studied adverse childhood experiences (ACEs) and has been shown to have negative effects on health throughout the life cycle. ${ }^{6}$ It has been associated with a higher risk of depression 7,8 and suicide, ${ }^{9}$ lower academic achievement, ${ }^{10}$ lower occupational position, ${ }^{11}$ higher separation rates ${ }^{12}$ and a higher probability of psychosis. ${ }^{13}$ In terms of physical health, early parental death has been associated with worse health perception ${ }^{14}$ and more somatic symptoms, ${ }^{15}$ as well as higher mortality, ${ }^{16}$ cardiovascular disease, ${ }^{4,5,17}$ self-harm ${ }^{18}$ and an increased risk of dementia. ${ }^{19-26}$

Previous studies have identified certain mechanisms involved in the association between early parental death and the risk of dementia and other pathologies associated with older age: stress, ${ }^{27,28}$ increased inflammatory processes, ${ }^{29}$ alterations of the hypothalamic-pituitary-adrenal axis ${ }^{30}$ and shorter telomeres on chromosomes. ${ }^{31,32}$

Research into the relationship between early parental death and dementia and/or severe cognitive impairment in the elderly has confirmed a general increased risk (odds ratios (OR): $1.52-6.41)^{19-26}$, although the results vary according to gender and age at the time of parental death. In a prospective longitudinal study, Persson and Skoog (1996) ${ }^{19}$ found that the death of a parent before the age of 16 was associated with a relative risk (RR) of developing dementia of 6.3 (95\% Cl: 1.8-21.1). In contrast, in Fu's study (2020), ${ }^{20}$ only the 
death of the mother before the age of 16 was associated with severe cognitive decline in men $(\mathrm{OR}=1.52,95 \% \mathrm{Cl}: 1.01-2.28)$, though not in women.

Other authors have reported different age ranges. Conde-Sala $(2003)^{21}$ found that the death of the father before the age of 20 was associated with an increased risk of dementia in women. In Norton et al. (2009), ${ }^{22}$ the father's death before the age of four resulted in a threefold increase in the dementia risk, without differences for gender and education and after adjustment for APOE-4. With a larger sample, the same authors (Norton et al., 2011) ${ }^{23}$ also found a greater risk in the case of the father's death before the age of five and the mother's death between 11 and 17 years. In both cases, female gender, older age and APOE4 were associated with a greater risk of dementia.

Whalley et al. (2013) ${ }^{24}$ found an increased risk of dementia with the death of either parent before the age of 11 , which was also associated with female gender, older age and APOE-4. In Wei et al. (2014), ${ }^{25}$ early parental death was associated with an increased risk of dementia in the whole sample. In the study by Ravona-Springer et al. $(2012)^{26}$ which included data only on men (0-18 years), early parental death, either of the mother or the father, was associated with a higher risk of dementia.

In view of the heterogeneity of the results of previous studies and also bearing in mind the small size of some samples, the present study aimed to explore the association between early parental death and the risk of dementia according to age ranges, gender of parents and participants, schooling and income, using a large representative sample of older Europeans. 
We hypothesized that individuals with early parental death would have a higher prevalence of dementia.

The specific objectives of the present study were: 1 . To determine the frequency of early parental death in childhood and adolescence and its association with the risk of dementia in adult life; and 2 . To examine the risk factors associated with early parental death in people with and without dementia.

\section{MATERIAL AND METHODS}

\subsection{Study design}

Data for this population-based case-control study came from the seventh wave of the "Survey of Health, Ageing and Retirement in Europe" (SHARE), corresponding to the year 2017 and including people born between 1912 and 1967. The SHARE study provided information on sociodemographic aspects and on physical and mental health status. ${ }^{33}$ The seventh wave collected data from people over 50 years of age from 27 European countries: Austria, Germany, Sweden, Spain, Italy, France, Denmark, Greece, Switzerland, Belgium, Israel, Czechia, Poland, Luxembourg, Hungary, Portugal, Slovenia, Estonia, Croatia, Lithuania, Bulgaria, Cyprus, Finland, Latvia, Malta, Romania, and Slovakia. Average rates of individual response were around $69.6 \%$, ranging from $39.01 \%$ in Slovakia to $89.05 \%$ in Greece. ${ }^{33}$

SHARE wave 7 comprised 76,250 individuals. The main sample of the present study, i.e., those for whom data on the year of parents' deaths were available, totalled $65,997(86.8 \%)$ 
people; 3,754 (4.9\%) people with both parents alive and 6,249 (8.2\%) people for whom no data on parental death were available were not included in the study. The research was approved by the Ethics Committee of Girona Biomedical Institute.

\subsection{Measures}

- Periods of parental death. The year of parental death and the year of the participants' birth were used to establish participants' age periods at time of parental death: 0-5, 6-10, $11-16,17-20$ and $>21$ years. The analysis of the risk of dementia focused on the period of early parental death, i.e., when the participants were aged $\leq 16$ years. Previous authors have established this age as the most relevant for assessing the effect of early parental death ( $\leq$ 16 years) on the health of the elderly..$^{11,15,19,34}$

- Sociodemographic data. The following data were recorded: age ( $<65$ / $\geq 65$ years), gender (male / female), marital status (married, widowed, separated-divorced or never married), mean years of schooling ( $<11$ / $\geq 11$ years), economic difficulties (yes/no) and income in percentiles $(\leq 50 />50)$.

- Functional state. Five basic daily life activities (dressing, bathing, eating, cutting up food, walking across a room and getting in or out of bed) and five instrumental activities (telephone calls, taking medication, managing money, shopping for groceries and preparing a hot meal) were examined by assessing the presence or absence of the activity $(0 / \geq 1$ deficit). Four items were used to determine fragility (falling down, fear of falling down, dizziness and fatigue). On all scales, the higher the score, the greater the difficulty. 
- Cognition. The items of recent memory (range $=0-10)$ and deferred memory (range $=$ 0 -10) were used. The variable was dichotomized based on the mean of the scores $(<9 / \geq 9)$.

- Diseases. A total of 18 self-reported diseases were recorded, in response to the following question: "Has a doctor ever told you that you had [or do you currently have] any of the conditions listed on this sheet? By this we mean that a doctor has told you that you have this condition, and that you are either currently being treated for or bothered by this condition. The conditions are heart attack, hypertension, cholesterol, stroke, diabetes, chronic lung disease, cancer, stomach or duodenal ulcer, Parkinson disease, cataracts, hip or femoral fracture, other fractures, emotional disorders, rheumatoid arthritis, osteoarthritis, chronic kidney disease and dementia". The sum of the 18 diseases was also used as a variable.

- Personality traits. The short version of the Big Five Inventory (BFI-10) comprising 10 items was used to identify traits of Extraversion, Agreeableness, Conscientiousness, Neuroticism and Openness. ${ }^{35}$

\subsection{Statistical analysis}

The presence in adulthood of a total of 18 diseases was analysed according to the presence or absence of parental death in each age range. The frequency (mean and standard deviation) was examined and a Student's t-test was applied. A multivariate binomial logistic regression analysis was performed to analyse the degree of association between the adulthood diseases and parental death ( $\leq 16$ years). 
To establish the periods in which parental death presented significant results with respect to dementia, we performed a frequency analysis using the Chi-square test $\left(\chi^{2}\right)$ to calculate the differences in each of the age groups. The analysis was performed for the death of the father, the mother, the father or mother, and for the two together. A logistic regression analysis was performed for each of the age groups with parental death, indicating the crude and adjusted values for the variables age, gender and years of schooling.

Finally, a bivariate analysis was performed to identify the degree of association between the different variables and the groups with or without dementia. This was completed with a multivariate binomial logistic regression analysis with dementia status as dependent variable.

We also calculated the effect size, using Cohen's $d$ for the continuous variables (weak $<0.5$; moderate $0.5-0.8$ or strong $>0.8$ ), and Cramer's $\vee$ for the categorical variables (weak $<0.10$, moderate 0.30 or strong 0.50$).{ }^{36}$ For odds ratios, we used the values consistent with Cohen's d ( $<0.2$ vs OR $<1.5 ; 0.5$ vs OR $1.5-4.9 ;>0.8$ vs OR $>5.0) .{ }^{37}$

The level of statistical significance for contrasting the hypotheses was $<0.05$ with $95.0 \%$ confidence intervals according to the different analyses. The statistical analysis was performed using SPSS v24.0 for Windows (IBM SPSS Corp., Amonk, NY).

\section{RESULTS}

\subsection{Sample description}


The sample with data on parental death consisted of 65,997 people, of whom 1431 (2.2\%) had a diagnosis of dementia. Only 3754 subjects had two living parents, and only six (0.3\%) of these had dementia. Data on parental death were not available in 6249 subjects, and 410 (6.6\%) had a diagnosis of dementia (see Figure 1).

In all variables, the group with living parents had the most favourable data (younger, more education and cognition, less disease), and the group who had lost their parents had the least favourable. The complete data of the three groups can be found in supplementary Table 1.

Figure 1

In the main sample $(n=65,997)$, the mean age was $68.65 \pm 9.4$ years, with $43.1 \%$ men and $56.9 \%$ women. A total of $68.8 \%$ were married and $16.8 \%$ were widows/widowers. With regard to education, $59.5 \%$ had more than 11 years of schooling, and the average score for recent and deferred memory was $8.85 \pm 3.6$ on a scale of 20 points.

Medical conditions were recorded in $79.9 \%$ of the sample, as follows: hypertension (45.1\%), cholesterol (25.3\%), osteoarthritis (19.7\%), diabetes $(14.0 \%)$, heart attacks $(12.8 \%)$ and rheumatoid arthritis (10.2\%). In relation to the five personality traits (range 0-5), Extraversion had an average score of $3.49 \pm 0.9$, Agreeableness $3.66 \pm 0.8$, Conscientiousness $4.12 \pm 0.8$, Neuroticism $2.66 \pm 0.9$ and Openness $3.29 \pm 0.9$.

In the main sample the deceased parents were father $(n=62096,94.1 \%)$, mother $(n=$ $55635,84.3 \%)$, father or mother $(n=65997,100.0 \%)$, and both $(n=51734,78.4 \%)$. In terms 
of parental death in the participant age range of $\leq 16$ years: the father had died $(n=6034$, 9.7\%), mother $(n=2181,3.9 \%)$, father or mother $(n=8024,12.2 \%)$ or both $(n=191,0.4 \%)$.

\subsection{Presence of disease in adulthood according to the age at parental death}

A first analysis was performed to verify the presence of disease in adulthood in relation to early parental death. Using the variable "sum of the 18 diseases", a higher number of diseases were recorded in the $\leq 16$ years age range $(2.18 \pm 1.7$ vs $1.87 \pm 1.6 ; t=15.2, p$ $<0.001)$. In the 17-20 age range the differences were not significant. From the age of 21 onwards, the mean number of diseases was lower (1.88 \pm 1.6 vs $2.07 \pm 1.7 ; t=10.7, p$ $<0.001)$. The complete data set is shown in Table 1.

Table 1

A multivariate binomial logistic regression was performed with parental death at participant age $\leq 16$ years as a dependent variable, and with the 18 diseases as covariates. Dementia had the highest odds ratio $(\mathrm{OR}=1.63,95 \% \mathrm{Cl}=1.42-1.86)$, with a moderate effect size (>1.5). The complete data are shown in Table 2.

Table 2

\subsection{Dementia according to the age of participants at time of parental death}

Previous analyses (Table 2) justify focusing the study on the association of early parental deaths on dementia. Supplementary Table 2 shows the frequencies of the presence/absence of dementia in each of the age groups, differentiating between the deaths of the father, 
mother, either of the two, or both. Looking at the early deaths of the father or mother (third column), it can be seen that the rates of dementia compared to no dementia are higher until the age of 16 years. The data at the age of $0-5$ years are: Dementia, $n=95,6.6 \%$; No dementia, $\mathrm{n}=2596,4.0 \%$; $\nexists^{2}=24.5, p<0.001$. At participant age $10-11$ the data are:

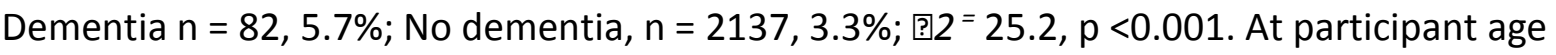
11-16 the data are: Dementia $n=109,7.6 \%$; No dementia, $n=3005,4.7 \%$; $2^{2}=27.3, p$ $<0.001$. And in the set of 0 to 16 years the data are: Dementia $n=286,20.0 \%$; No dementia, $\mathrm{n}=7738,12.0 \% ; \mathbb{P}^{2}=83.9, p<0.001$

The data for ages 17, 18, 19 and 20, analysed individually, did not differ significantly and so they were combined in a single age group (17-20 years). No significant differences were found here either: Dementia $n=72,5.0 \%$; No dementia, $n=2844,4.4 \% ; ?^{2}=1.3, p=0.254$. In the age group of 21 years and over, the proportions were reversed as there were significantly more cases without dementia: Dementia $n=1,073,75.0 \%$; No dementia, $n=$ 53984, 83.6\%; ? $^{2}=75.3, p<0.001$.

Table 3 shows the binary logistic regressions with the odds ratios for the different age groups. The crude ORs of the deaths of the father or mother together (third column), for age groups $0-5,6-10,11-16$ and $0-16$, were relatively high: $1.70,1.77,1.69$ and $1.83(p<0.05)$ respectively. When the regressions were adjusted with the variables age, gender and years of schooling they continued to be significant, although their values were slightly lower: 1.32, $1.51,1.56$, and $1.54(p<0.05)$ respectively. In the data for "both parents" (fourth column), the results were not significant due to the small sample size, and older age it was the 
variable that made the father's death non-significant in the adjusted model ( $0-5 b$ years). The complete data are shown in Table 3.

Table 3

\subsection{Factors associated with early parental death in people with and without dementia}

In the bivariate analysis, the most notable differences between participants with and without dementia with regard to early parental death ( $\leq 16$ years) were found in deficits in active daily living $(4.21 \pm 3.6$ vs $0.49 \pm 1.4, d=1.34)$, Cognition $(3.83 \pm 3.1$ vs $8.35 \pm 3.6, d=$ 1.32), Age ( $81.7 \pm 7.8$ vs $71.7 \pm 9.8, d=1.20)$, Sum of diseases $(3.86 \pm 2.1$ vs $2.12 \pm 1.6, d=$ $0.89)$, Frailty (1.69 \pm 1.3 vs $0.73 \pm 1.0, d=0.78)$, Neuroticism ( $3.07 \pm 0.8$ vs. $2.66 \pm 0.9, d=$ $0.45)$ and Emotional disorders $(57.7 \%$ vs $27.3, \mathrm{~V}=0.12)$. The complete data are shown in Table 4.

\section{Table 4}

A multivariate logistic analysis was performed with the whole sample, with the variable No-dementia / Dementia as the dependent variable and with the deaths of the father or mother ( $\leq 16$ years) as a covariate, to rank it hierarchically with respect to the possible confusion covariates: age, neuroticism, years of schooling, income and gender. The covariate early parental death continued to be significant $(\mathrm{OR}=1.50,95 \% \mathrm{Cl}=1.31-1.72, p<0.001)$, as did older age $(O R=5.92)$, greater neuroticism $(O R=2.94)$, fewer years of schooling $(O R=$ $1.84)$, and lower income $(O R=1.49)$. Gender was not significant. The complete results are shown in Table 5. 
Table 5

\section{DISCUSSION}

\subsection{Prevalence of early parental death}

Demographic studies provide some data on the magnitude of early parental death. The study by Parsons (2011), ${ }^{34}$ which analysed a British cohort of 1970, placed parental death at the age of 16 at $4.7 \%$. In a cohort study in the Netherlands, Van Poppel et al. $(2013)^{38}$ found that the prevalence of parental death at 15 years of age ranged from $13.4 \%$ in the 1900 1922 cohort to $3.0 \%$ in the $1975-1985$ cohort. In our sample, the rates of early parental death at participant age 16 years were higher (11.8\%); however, we also observed reductions in the more recent cohorts: $1912-1949$ (14.1\%) and 1950-1967 (7.8\%).

\subsection{Early parental death and diseases}

Many studies have linked parental death with depression. ${ }^{7,8}$ However, our data also confirm the negative effects on adult physical health. ${ }^{6,14-18}$ The study by Neeleman et al. $(2002)^{15}$ analysed 20 chronic diseases and found a higher risk in adults whose parents had died before they were 16 years old. 
We have not found any references that establish a hierarchy among physical illnesses in relation to early parental death. Most studies analyse the diseases individually, and the diseases most commonly studied are dementia ${ }^{19-26}$ and cardiovascular disease. ${ }^{4,5,17}$

\subsection{Early parental death and dementia}

In our study, in all age groups up to 16 years, parental death (death of the father, mother, or either father or mother) is associated with an increased risk of dementia, with moderate odds ratios. These results corroborate those of other studies; ${ }^{19,25}$ however, in other studies a greater risk was only observed in some age groups ${ }^{22-24,26}$ or for the death of the mother ${ }^{20}$ or the father ${ }^{22}$, with higher odds ratios than in our analysis. This heterogeneity in the results may be due to small sample sizes.

The greater risk was maintained in the models adjusted for age, gender and education. In the multivariate regression, risk associated with early parental death remained significant even after adding the possible confounding variables age, neuroticism, years of schooling and income. Neuroticism has already been documented as a risk factor for dementia ${ }^{39}$ and the loss of a parent may be associated with lower academic achievement and income. ${ }^{10}$ Some studies have found differences in relation to participant gender; ${ }^{20,23}$ however, gender was not relevant in our analysis.

\subsection{Biomarkers of adverse childhood experiences}


A recent review ${ }^{40}$ identified the biomarkers related to adverse childhood experiences:

inflammatory processes (IL-6, interleukin; CRP, C-reactive protein), cardio-metabolic systems (blood pressure), genetics (length of telomeres) and endocrine systems (cortisol).

Norton et al. (2017) ${ }^{29}$ found that people with two or more family deaths in childhood were $79 \%$ more likely to have high CRP in old age, emphasizing the relationship between childhood stress and inflammatory processes in old age. Multiple adverse childhood experiences, including parental death, have also been associated with higher blood pressure ${ }^{3}$ higher levels of IL-6 and shorter telomeres. ${ }^{41}$ Mitchell et al. (2017) ${ }^{31}$ found that children who had lost their father before nine years of age had the shortest telomeres. Early life stress, including parental death, has been associated with cell aging, with shorter telomeres and high copy numbers of mitochondrial DNA (mtDNA). ${ }^{32}$ Regarding endocrine systems, early parental death has been related to changes in the HPA (hypothalamicpituitary-adrenal) axis, with increased cortisol. ${ }^{30}$

A review on dementia ${ }^{27}$ found that there is sufficient proven evidence to consider adverse childhood experiences as a risk factor for this condition. Early life stress has been associated with deficits in various cognitive functions ${ }^{42}$ and with an increased risk of dementia. ${ }^{28}$ In addition, shorter telomeres were identified as a risk factor for dementia. ${ }^{43}$

\subsection{Clinical implications: interventions in adverse childhood experiences}

A recent review of the prevalence of adverse childhood experiences $(A C E)^{1}$ reported that 23.5\% of people in Europe had had one ACE and $18.7 \%$ two or more, while in North America 
$23.4 \%$ had had one ACE and $35.0 \%$ two or more. The authors emphasized the need for programmes and interventions to prevent ACEs or to mitigate their effects.

The recognition of this need has generated a wide variety of interventions for reducing the negative health consequences of ACEs, in both childhood and adulthood. The interventions for modifying the biological markers associated with stress, ${ }^{44}$ such as cortisol, ${ }^{45}$ telomeres ${ }^{46}$ and interleukin-IL6 ${ }^{47}$ stand out. Certain interventions have been specifically designed for early parental death, ${ }^{48,49}$ and have varying orientations: some are centred on increasing resilience $\mathrm{e}^{47,48,50}$ and others focus on implementing coping strategies. ${ }^{51}$

In general, interventions are directed at people who have had adverse childhood experiences, including adults, children and adolescents. In the last case, the programmes incorporate parents or caregivers into the treatment, highlighting the importance of warmth and supportiveness and a positive family upbringing.

\subsection{Strengths and limitations}

A strength of this study is the sample size $(65,997$ participants and 1431 cases of dementia). This sample size is the largest in the studies carried out to date on early parental death and dementia. However, the study has some limitations that should be mentioned. First, we found few data on parents' backgrounds, especially with regard to health and illness. Second, we could not rule out an information bias, because information on medical diagnoses was self-referred. Third, the number of lost cases with dementia and without data on parental death was relatively high (6.6\%). A fourth limitation is the impossibility of 
analysing the coexistence of other ACEs with early parental death (such as abuse, neglect, drug addiction, etc.).

\section{Acknowledgement}

This paper uses data from SHARE Waves 7 (DOIs: 10.6103/SHARE.w7.700), see Börsch-Supan et al. (2013) for methodological details.(1) The SHARE data collection has been funded by the European Commission through FP5 (QLK6-CT-2001-00360), FP6 (SHARE-I3: RII-CT-2006062193, COMPARE: CIT5-CT-2005-028857, SHARELIFE: CIT4-CT-2006-028812), FP7 (SHAREPREP: GA N²11909, SHARE-LEAP: GA N²27822, SHARE M4: GA N²61982) and Horizon 2020 (SHARE-DEV3: GA N676536, SERISS: GA N654221) and by DG Employment, Social Affairs \& Inclusion. Additional funding from the German Ministry of Education and Research, the Max Planck Society for the Advancement of Science, the U.S. National Institute on Aging (U01_AG09740-13S2, P01_AG005842, P01_AG08291, P30_AG12815, R21_AG025169, Y1AG-4553-01, IAG_BSR06-11, OGHA_04-064, HHSN271201300071C) and from various national funding sources is gratefully acknowledged(see www.share-project.org).

Conflict of Interest: None declared

Availability of data: These data were derived from the following resources available in the public domain: Survey of Health, Ageing and Retirement in Europe (SHARE). http://www.share-project.org/home0.html 


\section{REFERENCES}

1. Bellis MA, Hughes K, Ford K, Ramos Rodriguez G, Sethi D, Passmore J. Life course health consequences and associated annual costs of adverse childhood experiences across Europe and North America: a systematic review and meta-analysis. Lancet Public Health 2019;4:e517-28.

2. Williams MM, Kemp BR, Ferraro KF, Mustillo SA. Avoiding the Major Causes of Death: Does Childhood Misfortune Reduce the Likelihood of Being Disease Free in Later Life? J Gerontol B Psychol Sci Soc Sci 2019;74:170-80

3. Su S, Wang X, Pollock JS, Treiber FA, Xu X, Snieder H, et al. Adverse childhood experiences and blood pressure trajectories from childhood to young adulthood: the Georgia stress and Heart study. Circulation 2015;131:1674-81.

4. Halonen JI, Stenholm S, Pentti J, Kawachi I, Subramanian SV, Kivimäki M, et al. Childhood Psychosocial Adversity and Adult Neighborhood Disadvantage as Predictors of Cardiovascular Disease: A Cohort Study. Circulation 2015;132:371-9.

5. Doom JR, Mason SM, Suglia SF, Clark CJ. Pathways between childhood/ adolescent adversity, adolescent socioeconomic status, and long-term cardiovascular disease risk in young adulthood. Soc Sci Med 2017;188:166-75.

6. Luecken LJ, Roubinov DS. Pathways to lifespan health following childhood parental death. Soc Personal Psychol Compass 2012;6:243-57.

7. Appel CW, Frederiksen K, Hjalgrim H, Dyregrov A, Dalton SO, Dencker A, et al. Depressive symptoms and mental health-related quality of life in adolescence and young adulthood after early parental death. Scand J Public Health 2019;47:182-92.

8. Pham S, Porta G, Biernesser C, Walker Payne M, lyengar S, Melhem N, et al. The Burden of Bereavement: Early-Onset Depression and Impairment in Youths Bereaved by Sudden Parental Death in a 7-Year Prospective Study. Am J Psychiatry 2018;175:887-96. 
9. Guldin MB, Li J, Pedersen HS, Obel C, Agerbo E, Gissler M, et al. Incidence of Suicide Among Persons Who Had a Parent Who Died During Their Childhood: A PopulationBased Cohort Study. JAMA Psychiatry 2015;72:1227-34.

10. Berg L, Rostila M, Saarela J, Hjern A. Parental death during childhood and subsequent school performance. Pediatrics 2014;133:682-9.

11. Rosenbaum-Feldbrügge M. The Impact of Parental Death in Childhood on Sons' and Daughters' Status Attainment in Young Adulthood in the Netherlands, 1850-1952. Demography 2019;56:1827-54.

12. Høeg BL, Johansen C, Christensen J, Frederiksen K, Dalton SO, Dyregrov A, et al. Early parental loss and intimate relationships in adulthood: A nationwide study. Dev Psychol 2018;54:963-74.

13. Misra S, Gelaye B, Koenen KC, Williams DR, Borba CPC, Quattrone D, et al. Early Parental Death and Risk of Psychosis in Offspring: A Six-Country Case-Control Study. J Clin Med 2019;8:1081.

14. Phillips SP, Carver L. Early parental loss and self-rated health of older women and men: a population-based, multi-country study. PloS one 2015;10:e0120762.

15. Neeleman J, Sytema S, Wadsworth M. Propensity to psychiatric and somatic ill-health: evidence from a birth cohort. Psychol Med 2002;32:793-803.

16. Smith KR, Hanson HA, Norton MC, Hollingshaus MS, Mineau GP. Survival of offspring who experience early parental death: early life conditions and later-life mortality. Soc Sci Med 2014;119:180-90.

17. Schooling CM, Jiang C, Lam TH, Zhang W, Cheng KK, Leung GM. Parental death during childhood and adult cardiovascular risk in a developing country: the Guangzhou Biobank Cohort Study. PLoS One 2011;6:e19675.

18. Rostila M, Berg L, Arat A, Vinnerljung B, Hjern A. Parental death in childhood and selfinflicted injuries in young adults-a national cohort study from Sweden. Eur Child Adolesc Psychiatry 2016;25:1103-11. 
19. Persson G, Skoog I. A prospective population study of psychosocial risk factors for late onset dementia. Int J Geriatr Psychiatry 1996;11:15-22.

20. Fu R. Early Parental Death and Cognitive Impairment in Late Life: A Cohort Study. Sage Open 2019;9: https://doi.org/10.1177/2158244019879135

21. Conde-Sala JL. Psychosocial risk factors and premorbid personality in patients with dementia: a case-control study. Rev Esp Geriatr Gerontol 2003;38:10-24

22. Norton MC, Ostbye T, Smith KR, Munger RG, Tschanz JT. Early parental death and latelife dementia risk: Findings from the Cache County Study. Age Ageing 2009;38:340-3.

23. Norton MC, Smith KR, Ostbye T, Tschanz JT, Schwartz S, Corcoran C, et al. Early parental death and remarriage of widowed parents as risk factors for Alzheimer disease: The Cache County study. Am J Geriatr Psychiatry 2011;19:814-24.

24. Whalley L, Staff RT, Murray AD, Deary IJ, Starr JM. Genetic and environmental factors in late onset dementia: possible role for early parental death. Int J Geriatr Psychiatry 2013;28:75-81.

25. Wei CJ, Cheng Y, Zhang Y, Sun F, Zhang WS, Zhang MY. Risk factors for dementia in highly educated elderly people in Tianjin, China. Clin Neurol Neurosurg 2014;122: 4-8.

26. Ravona-Springer R, Beeri MS, Goldbourt U. Younger age at crisis following parental death in male children and adolescents is associated with higher risk for dementia at old age. Alzheimer Dis Assoc Disord 2012;26:68-73.

27. Hoeijmakers L, Lesuis SL, Krugers H, Lucassen PJ, Korosi A. A preclinical perspective on the enhanced vulnerability to Alzheimer's disease after early-life stress. Neurobiol Stress 2018;8:172-85.

28. Radford K, Delbaere K, Draper B, Mack HA, Daylight G, Cumming R, et al. Childhood Stress and Adversity is Associated with Late-Life Dementia in Aboriginal Australians. Am J Geriatr Psychiatry 2017;25:1097-106.

29. Norton MC, Hatch DJ, Munger RG, Smith KR. Family Member Deaths in Childhood Predict Systemic Inflammation in Late Life. Biodemography Soc Biol 2017;63:104-15. 
30. Tyrka AR, Wier L, Price LH, Ross N, Anderson GM, Wilkinson CW, et al. Childhood parental loss and adult hypothalamic-pituitary-adrenal function. Biol Psychiatry 2008;63:1147-54.

31. Mitchell C, McLanahan S, Schneper L, Garfinkel I, Brooks-Gunn J, Notterman D. Father Loss and Child Telomere Length. Pediatrics 2017;140:e20163245.

32. Ridout KK, Khan M, Ridout SJ. Adverse Childhood Experiences Run Deep: Toxic Early Life Stress, Telomeres, and Mitochondrial DNA Copy Number, the Biological Markers of Cumulative Stress. Bioessays 2018;40:e1800077.

33. Bergmann M, Scherpenzeel A, Börsch-Supan A. (Eds). Share Wave 7 Methodology: Panel innovations and life histories. Munich: Munich Center for the Economics of Aging and the Max Planck Institute for Social Law and Social Policy; 2019

34. Parsons S. Long-term Impact of Childhood Bereavement: Preliminary Analysis of the 1970 British Cohort Study (BCS70). London: Child Well-being Research Centre; 2011.

35. Rammstedt B, John OP. Measuring personality in one minute or less: A 10-item short version of the Big Five Inventory in English and German. J Res Pers 2007;41:203-12.

36. Cohen J. Statistical Power Analysis for the Behavioral Sciences, 2nd Edition. Hillsdale, NJ: Lawrence Erlbaum; 1988.

37. Chen $\mathrm{H}$, Cohen $\mathrm{P}$, Chen $\mathrm{S}$. How big is a big odds ratio? Interpreting the magnitudes of odds ratios in epidemiological studies. Commun Stat Simul Comput 2010;39:860-4.

38. Van Poppel F, Schenk N, van Gaalen R. Demographic Transitions and Changes in the Living Arrangements of Children: The Netherlands 1850-2010. Popul Res Policy Rev 2013;32:243-60.

39. Terracciano A, Sutin AR, An Y, O'Brien RJ, Ferrucci L, Zonderman AB, et al. Personality and risk of Alzheimer's disease: new data and meta-analysis. Alzheimers Dement 2014;10:179-86.

40. Deighton S, Neville A, Pusch D, Dobson K. Biomarkers of adverse childhood experiences: A scoping review. Psychiatry Res 2018;269:719-32. 
41. Kiecolt-Glaser JK, Gouin JP, Weng NP, Malarkey WB, Beversdorf DQ, Glaser R.

Childhood adversity heightens the impact of later-life caregiving stress on telomere length and inflammation. Psychosom Med 2011;73:16-22.

42. Pechtel P, Pizzagalli DA. Effects of early life stress on cognitive and affective function: an integrated review of human literature. Psychopharmacology (Berl) 2011;214:55-70.

43. Forero DA, González-Giraldo Y, López-Quintero C, Castro-Vega LJ, Barreto GE, Perry G. Meta-analysis of Telomere Length in Alzheimer's Disease. J Gerontol A Biol Sci Med Sci 2016;71:1069-73.

44. Purewal Boparai SK, Au V, Koita K, Oh DL, Briner S, Burke Harris N, et al. Ameliorating the biological impacts of childhood adversity: A review of intervention programs. Child Abuse Negl 2018;81:82-105.

45. Slopen N, McLaughlin KA, Shonkoff JP. Interventions to improve cortisol regulation in children: a systematic review. Pediatrics 2014;133:312-26.

46. Brody GH, Yu T, Beach SR, Philibert RA. Prevention effects ameliorate the prospective association between nonsupportive parenting and diminished telomere length. Prev Sci 2015;16:171-80.

47. Gouin JP, Caldwell W, Woods R, Malarkey WB. Resilience Resources Moderate the Association of Adverse Childhood Experiences with Adulthood Inflammation. Ann Behav Med 2017;51:782-6.

48. Sandler IN, Wolchik SA, Ayers TS, Tein JY, Luecken L. Family Bereavement Program (FBP) Approach to Promoting Resilience Following the Death of a Parent. Fam Sci 2013;4:1.

49. Bergman AS, Axberg U, Hanson E. When a parent dies - a systematic review of the effects of support programs for parentally bereaved children and their caregivers. BMC Palliat Care 2017;16:39.

50. Bellis MA, Hardcastle K, Ford K, Hughes K, Ashton K, Quigg Z, et al. Does continuous trusted adult support in childhood impart life-course resilience against adverse 
childhood experiences - a retrospective study on adult health-harming behaviours and mental well-being. BMC Psychiatry 2017;17:110.

51. Sheffler JL, Piazza JR, Quinn JM, Sachs-Ericsson NJ, Stanley IH. Adverse childhood experiences and coping strategies: identifying pathways to resiliency in adulthood. Anxiety Stress Coping 2019;32:594-609. 
TABLE 1 Age of the subject at the death of the parents and diseases

\begin{tabular}{|c|c|c|c|c|c|c|}
\hline & & \multicolumn{2}{|c|}{ Number of diseases } & \multirow{2}{*}{\multicolumn{3}{|c|}{ Differences }} \\
\hline & & Age & Other ages & & & \\
\hline $\begin{array}{c}\text { parental } \\
\text { death }\end{array}$ & $\mathbf{N}$ groups & Mean (D) & Mean (SD) & $t$ & $p$ & $d$ \\
\hline 0-5 / Other & 2691 / 63306 & $2.29(1.7)$ & $1.89(1.6)$ & 11.4 & $<0.001$ & 0.23 \\
\hline 6-10 / Other & 2219 / 63778 & $2.20(1.7)$ & $1.90(1.6)$ & 8.1 & $<0.001$ & 0.18 \\
\hline 11-16 / Other & 3114 / 62883 & $2.10(1.7)$ & $1.90(1.6)$ & 6.3 & $<0.001$ & 0.11 \\
\hline 0-16 / Other & 8024 / 57973 & $2.18(1.7)$ & $1.87(1.6)$ & 15.2 & $<0.001$ & 0.18 \\
\hline 17-20 / Other & 2916 / 63081 & $1.93(1.6)$ & $1.91(1.6)$ & 0.9 & 0.358 & 0.01 \\
\hline$\geq 21$ / Other & 55057 / 10940 & $1.88(1.6)$ & $2.07(1.7)$ & 10.7 & $<0.001$ & 0.11 \\
\hline
\end{tabular}


TABLE 2 Multivariate logistic regression. Diseases and early parental death ( $\leq 16$ years)

\begin{tabular}{lccc}
\hline Method: Forward Wald & OR & $95 \% \mathrm{Cl}$ & $\boldsymbol{p}$ \\
\hline Diseases & 1.63 & $1.42-1.86$ & $<\mathbf{0 . 0 0 1}$ \\
Dementia & 1.44 & $1.26-1.64$ & $<\mathbf{0 . 0 0 1}$ \\
Chronic kidney & 1.37 & $1.27-1.48$ & $<\mathbf{0 . 0 0 1}$ \\
Cataracts & 1.36 & $1.27-1.45$ & $<\mathbf{0 . 0 0 1}$ \\
Heart attack & 1.18 & $1.09-1.27$ & $<\mathbf{0 . 0 0 1}$ \\
Rheumatoid arthritis & 1.18 & $1.06-1.31$ & $\mathbf{0 . 0 0 3}$ \\
Stroke & 1.16 & $1.10-1.21$ & $<\mathbf{0 . 0 0 1}$ \\
Hypertension & 1.14 & $1.02-1.27$ & $\mathbf{0 . 0 1 6}$ \\
Stomach and duodenal ulcer & 1.08 & $1.02-1.15$ & $\mathbf{0 . 0 0 9}$ \\
Other diseases & 0.91 & $0.86-0.97$ & $\mathbf{0 . 0 0 3}$ \\
Osteoarthritis & & &
\end{tabular}

Note. Dependent variable: death of parents at $\leq 16$ years. $0=$ Other ages $(n=57973) ; 1=\leq$ 16 years $(n=8024)$.

OR, Odds ratio; $\mathrm{Cl}$, Confidence interval; $p<0.05$ are shown in bold.

Effect size for OR: small $=<1.5$, medium $=1.5-4.9$, strong $=>5.0$ 
TABLE 3 Multivariate binary logistic regression. Odds ratio for dementia in adulthood according to the age of the subject at the death of the parents

\begin{tabular}{|c|c|c|c|c|c|c|c|c|}
\hline \multirow[b]{2}{*}{ Years of death } & \multicolumn{2}{|c|}{$\begin{array}{l}\text { Father } \\
\text { Dementia, } n=1336\end{array}$} & \multicolumn{2}{|l|}{$\begin{array}{l}\text { Mother } \\
\text { Dementia, } n=1345\end{array}$} & \multicolumn{2}{|c|}{$\begin{array}{l}\text { Father or Mother } \\
\text { Dementia, } n=1431\end{array}$} & \multicolumn{2}{|c|}{$\begin{array}{l}\text { Both parents } \\
\text { Dementia, } N=1250\end{array}$} \\
\hline & OR $(95 \% \mathrm{Cl})$ & $p$ & OR $(95 \% \mathrm{Cl})$ & $p$ & OR $(95 \% \mathrm{Cl})$ & $p$ & OR $(95 \% \mathrm{Cl})$ & $p$ \\
\hline $0-5^{a}$ & 1.49 (1.16-1.92) & 0.002 & $2.00(1.40-2.87)$ & $<0.001$ & $1.70(1.37-2.10)$ & $<0.001$ & $1.24(0.30-5.08)$ & 0.762 \\
\hline $0-5^{b}$ & $1.18(0.92-1.53)$ & 0.188 & $1.73(1.21-2.49)$ & 0.003 & $1.32(1.07-1.63)$ & 0.010 & $1.11(0.27-4.58)$ & 0.879 \\
\hline $6-10^{a}$ & $1.69(1.29-2.21)$ & $<0.001$ & $1.85(1.25-2.73)$ & 0.002 & $1.77(1.41-2.23)$ & $<0.001$ & $2.64(0.82-8.49)$ & 0.104 \\
\hline $6-10^{b}$ & $1.47(1.12-1.93)$ & 0.005 & $1.67(1.13-2.47)$ & 0.010 & $1.51(1.20-1.89)$ & $<0.001$ & $2.18(0.67-7.07)$ & 0.195 \\
\hline $11-16^{a}$ & $1.62(1.29-2.05)$ & $<0.001$ & $1.49(1.04-2.14)$ & 0.031 & $1.69(1.38-2.06)$ & $<0.001$ & . & .......... \\
\hline $11-16^{b}$ & $1.54(1.22-1.95)$ & $<0.001$ & $1.46(1.01-2.11)$ & 0.042 & $1.56(1.28-1.91)$ & $<0.001$ & . & ......... \\
\hline $0-16^{a}$ & $1.67(1.43-1.94)$ & $<0.001$ & $1.79(1.44-2.23)$ & $<0.001$ & 1.83 (1.61-2.09) & $<0.001$ & $1.08(0.44-2.64)$ & 0.856 \\
\hline $0-16^{b}$ & $1.44(1.23-1.67)$ & $<0.001$ & $1.64(1.32-2.04)$ & $<0.001$ & $1.54(1.35-1.76)$ & $<0.001$ & $0.95(0.39-2.33)$ & 0.920 \\
\hline $17-20^{a}$ & $1.21(0.92-1.59)$ & 0.169 & $0.82(0.51-1.34)$ & 0.437 & $1.15(0.90-1.46)$ & 0.254 & & .......... \\
\hline $17-20^{b}$ & $1.26(0.96-1.66)$ & 0.095 & $0.82(0.50-1.33)$ & 0.415 & $1.13(0.89-1.44)$ & 0.301 & & ......... \\
\hline
\end{tabular}




\begin{tabular}{|c|c|c|c|c|c|c|c|c|}
\hline$\geq 21^{\mathrm{a}}$ & $0.63(0.55-0.72)$ & $<0.001$ & $0.66(0.54-0.80)$ & $<0.001$ & $0.58(0.52-0.66)$ & $<0.001$ & $1.24(0.51-3.02)$ & 0.629 \\
\hline$\geq 21^{b}$ & $0.70(0.61-0.80)$ & $<0.001$ & $0.70(0.57-0.86)$ & 0.001 & $0.64(0.57-0.73)$ & $<0.001$ & $1.34(0.55-3.27)$ & 0.515 \\
\hline
\end{tabular}

Note. Dependent variable: 0 = No dementia, 1 = Dementia. Co-variables: Years of death. OR, Odds ratio; Cl, Confidence interval; $p<0.05$ are shown in bold.

${ }^{\mathrm{a}}$ Crude value, ${ }^{\mathrm{b}}$ Adjusted for age, gender and years of schooling. Effect size for OR, small $=<1.5$, medium $=1.5-4.9$, strong $=>5.0$ 
TABLE 4 Clinical and sociodemographic data. Dementia vs No-Dementia in death of parents ( $\leq 16$ years)

\begin{tabular}{|c|c|c|c|c|c|}
\hline & \multirow{2}{*}{$\begin{array}{c}\text { Dementia } \\
n=286\end{array}$} & \multirow{2}{*}{$\begin{array}{c}\text { No-Dementia } \\
n=7738\end{array}$} & \multicolumn{3}{|c|}{ Differences } \\
\hline & & & $t / Z^{2}$ & $p$ & $d / V$ \\
\hline Death of parents ( $\leq 16$ years), $n(\%)$ & $286(20.0)$ & $7738(12.0)$ & 83.9 & $<0.001$ & 0.04 \\
\hline Age, mean (SD) & $81.87(7.8)$ & $71.17(9.8)$ & 22.4 & $<0.001$ & 1.20 \\
\hline$>65$ years, $n(\%)$ & $279(97.6)$ & $5625(72.7)$ & 87.6 & $<0.001$ & 0.10 \\
\hline Gender (female), $n$ (\%) & $166(58.0)$ & $4474(57.8)$ & 0.0 & 0.940 & 0.00 \\
\hline \multicolumn{6}{|l|}{ Marital status, $n(\%)$} \\
\hline Married & $134(47.2)$ & $4935(63.8)$ & 50.5 & $<0.001$ & 0.08 \\
\hline Widowed & $110(38.7)$ & $1679(21.7)$ & & & \\
\hline Divorced & $20(7.0)$ & $710(9.2)$ & & & \\
\hline Single & $20(7.0)$ & $406(5.3)$ & & & \\
\hline Years of schooling, mean (SD) & $8.88(4.1)$ & $10.35(4.0)$ & 6.0 & $<0.001$ & 0.36 \\
\hline$<11$ years, $n(\%)$ & $182(63.6)$ & 3649 (47.2) & 30.0 & $<0.001$ & 0.06 \\
\hline Economic difficulties, $n(\%)$ & $144(50.3)$ & $3437(44.4)$ & 3.9 & 0.047 & 0.02 \\
\hline Income (10-50 perc.), n (\%) & $133(46.8)$ & 2845 (36.8) & 11.7 & 0.001 & 0.04 \\
\hline ADL deficits, mean (SD) & $4.21(3.6)$ & 0.49 (1.4) & 17.3 & $<0.001$ & 1.34 \\
\hline$\geq 1, n(\%)$ & $216(75.5)$ & $1363(17.6)$ & 585.1 & $<0.001$ & 0.27 \\
\hline Frailty, mean (SD) & $1.69(1.3)$ & $0.73(1.0)$ & 11.5 & $<0.001$ & 0.78 \\
\hline Cognition (recall), mean (SD) & $3.83(3.1)$ & $8.35(3.6)$ & 23.8 & $<0.001$ & 1.32 \\
\hline $0-8$ points, $n(\%)$ & $269(94.1)$ & $3984(44.6)$ & 200.6 & $<0.001$ & 0.16 \\
\hline \multicolumn{6}{|l|}{ Personality, mean (SD } \\
\hline Extraversion & $3.36(0.9)$ & $3.50(0.9)$ & 1.9 & 0.055 & 0.15 \\
\hline Agreeableness & $3.61(0.8)$ & $3.67(0.8)$ & 0.8 & 0.387 & 0.07 \\
\hline Conscientiousness & $3.96(0.9)$ & $4.13(0.8)$ & 2.4 & 0.014 & 0.19 \\
\hline Neuroticism & $3.07(0.8)$ & $2.66(0.9)$ & 7.9 & $<0.001$ & 0.45 \\
\hline$>2.5, n(\%)$ & $207(72.4)$ & $3717(48.0)$ & 65.4 & $<0.001$ & 0.09 \\
\hline Openness & $3.04(0.8)$ & $3.29(0.9)$ & 3.7 & $<0.001$ & 0.27 \\
\hline Depression ( $\geq 4$ EURO-D) & $165(57.7)$ & $2112(27.3)$ & 125.3 & $<0.001$ & 0.12 \\
\hline \multicolumn{6}{|l|}{ Diseases, $n(\%)$} \\
\hline Emotional disorders & $67(23.4)$ & $530(6.8)$ & 110.0 & $<0.001$ & 0.12 \\
\hline Parkinson & 17 (5.9) & 70 (0.9) & 65.3 & $<0.001$ & 0.09 \\
\hline Stroke & $44(15.4)$ & $407(5.3)$ & 53.2 & $<0.001$ & 0.08 \\
\hline Cataracts & $59(20.6)$ & $883(11.4)$ & 22.6 & $<0.001$ & 0.05 \\
\hline Fracture (hip, femoral) & $15(5.2)$ & $155(2.0)$ & 13.9 & $<0.001$ & 0.04 \\
\hline Heart attack & $69(24.1)$ & 1310 (16.9) & 10.0 & 0.002 & 0.03 \\
\hline Chronic lung & $30(10.5)$ & $491(6.3)$ & 7.8 & 0.005 & 0.03 \\
\hline Diabetes & $63(22.0)$ & 1229 (15.9) & 7.7 & 0.005 & 0.03 \\
\hline Rheumatoid arthritis & $50(17.5)$ & 949 (12.3) & 6.8 & 0.009 & 0.03 \\
\hline Sum of 18 diseases, mean (SD) & $3.86(2.1)$ & $2.12(1.6)$ & 13.2 & $<0.001$ & 0.89 \\
\hline \multicolumn{6}{|l|}{ Parents' critical events *, $n$ (\%) } \\
\hline Father & $125(43.7)$ & 2839 (36.7) & 5.8 & 0.016 & 0.03 \\
\hline
\end{tabular}


Mother

Years of schooling, mean (SD)

\section{Father}

8.70 (2.9)

$1.8 \quad 0.061$

0.14

Mother

Note. t, Student's t-test; $\chi 2$, Pearson Chi-Square; Effect size: d, Cohen's d (small = 0.2, medium =0.5, large =0.8); $V=$ Cramer's (df1 = small: $\leq 0.10$, medium: 0.11-0.49, large: $\geq 0.50$ ); ADL: activities of daily living; $p$-values $<0.05$ are shown in bold. *Critical events: Imprisonment, labour camp, concentration camp, deportation, engaged in combat, serious damage to health or injury, deaths 
TABLE 5 Multivariate binary logistic regression. No dementia vs Dementia

\begin{tabular}{llccc}
\hline \multicolumn{2}{l}{ Method: Enter together } & OR & $95 \% \mathrm{Cl}$ & $\mathrm{p}$ \\
\hline Age & $(\geq 65)$ & 5.92 & $4.86-7.17$ & $<0.001$ \\
Neuroticism & $(>2.6)$ & 2.94 & $2.61-3.31$ & $<0.001$ \\
Years of schooling & $(<11$ years $)$ & 1.84 & $1.64-2.05$ & $<0.001$ \\
Death of parents & $(\leq 16$ years) & 1.50 & $1.31-1.72$ & $<\mathbf{0 . 0 0 1}$ \\
Income & $(10-50$ perc.) & 1.49 & $1.34-1.67$ & $<0.001$ \\
Gender & (male) & 1.10 & $0.99-1.23$ & 0.079 \\
\hline
\end{tabular}

Note. Dependent variable: $0=$ No dementia $(n=64566), 1=$ Dementia $(n=1431)$. Odds ratio; $\mathrm{Cl}$, Confidence interval; $p<0.05$ are shown in bold. Effect size for OR, small $=<1.5$, medium $=1.5-4.9 ;$ strong $=>5.0$. Collinearity, Tol: 0.94-0.99; VIF: 1.00-1.06; Index of Condition: 17.5 


\section{Figure captions}

FIGURE 1 Flowchart describing the analysed sample 


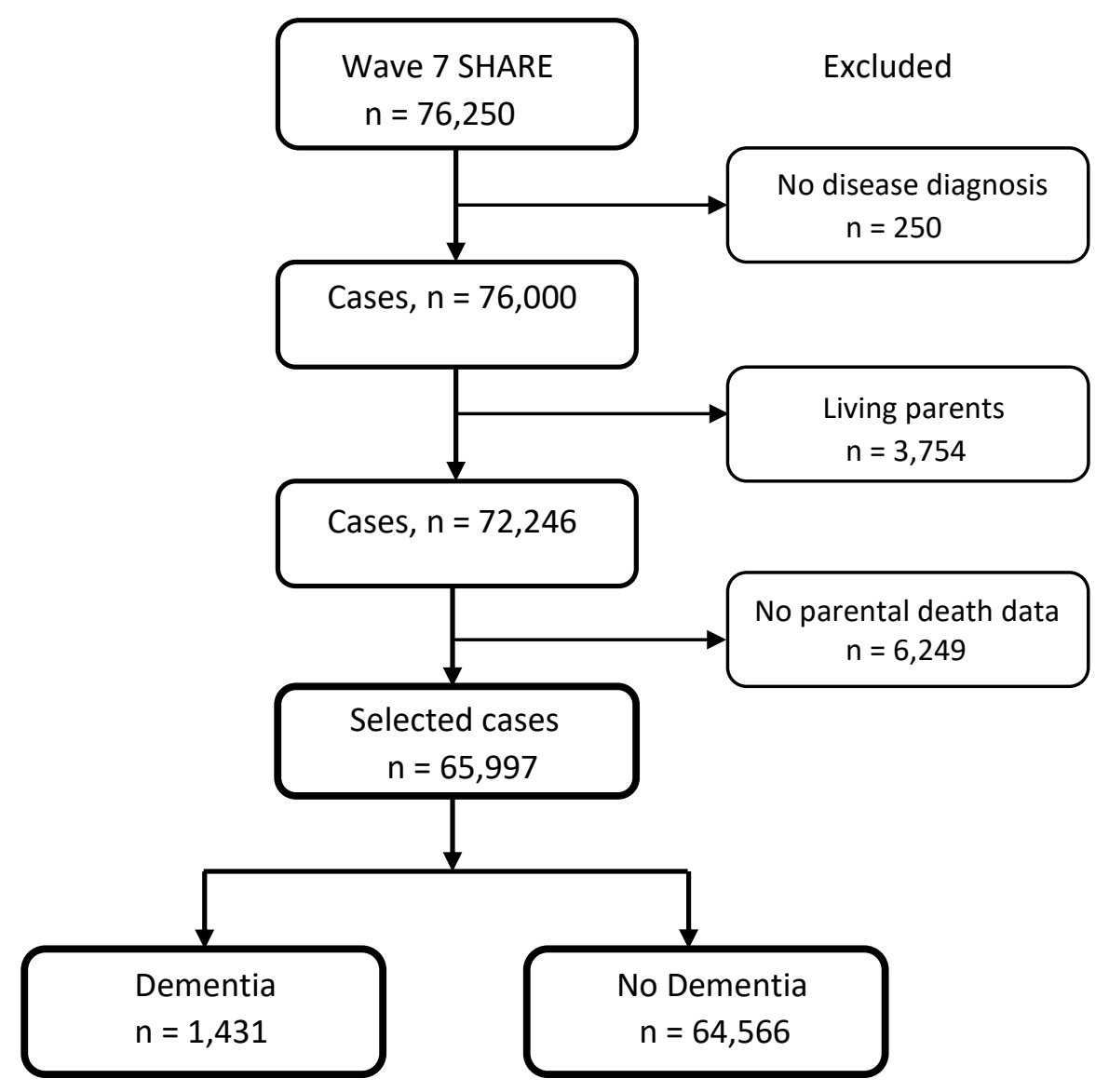

